\title{
Expression and significance of protein-degrading enzymes in cartilage and subchondral bone in osteoarthritis
}

\section{Peidong Pu}

Shihezi University School of Medicine

Weishan Wang ( $D$ wwsmc2002@sina.com)

HAN F

Shihezi University School of Medicine

Q-Y MA

Shihezi University School of Medicine

\section{T-Y MA}

Shihezi University School of Medicine

\section{D-F MENG}

Shihezi University School of Medicine

W-P ZHOU

Shihezi University School of Medicine

\section{Z-J ZHU}

Shihezi University School of Medicine

M-Y WANG

Shihezi University School of Medicine

\section{WANG}

Shihezi University School of Medicine

CSHI

Shihezi University School of Medicine

\section{Research article}

Keywords: Osteoarthritis (OA); Transforming growth factor beta 1 (TGF $\beta 1$ ); Subchondral bone; Bone remodeling

Posted Date: August 16th, 2019

DOl: https://doi.org/10.21203/rs.2.13081/v1 
License: (c) (i) This work is licensed under a Creative Commons Attribution 4.0 International License. Read Full License 


\section{Abstract}

Background TGF $\beta 1$ plays an important role in the metabolism of articular cartilage and bone; however, the pathological mechanism and targets of TGF $\beta 1$ in cartilage degradation and uncoupling of subchondral bone remodeling remain unclear. Therefore, in this study, we investigated the relationship between TGF $\beta 1$ and major protein-degrading enzymes, and evaluated the role of high levels of active TGF $\beta 1$ in the thickening of subchondral bone and calcification of articular cartilage. Materials and methods The expression of TGF $\beta 1$ and protein-degrading enzymes in clinical samples of articular cartilage and subchondral bone obtained from the knee joint of patients with osteoarthritis was detected by immunohistochemistry. The expression levels of TGF $\beta 1$, MMP-3, MMP-13 and IL-1 $\beta$ in cartilage and subchondral bone tissues were detected by absolute real-time quantitative RT-PCR. The expression of TGF $\beta 1$, nestin and osterix in subchondral bone was detected by Western blot analysis and immunohistochemistry. The degree of subchondral bone thickening was determined by micro-computed tomography (CT) imaging. Results Expression of TGF $\beta 1$ and cartilage-degrading enzymes was higher in the cartilage-disrupted group than that in the intact group. Furthermore, expression of TGF $\beta 1$, nestin and osterix was significantly higher in the OA group than that in the control group. Micro-CT imaging showed that the OA group had abnormal hyperplasia of subchondral bone. Conclusions The data suggest that highly active TGF $\beta 1$ activates the expression of cartilage-degrading enzymes. Abnormally activated TGF $\beta 1$ may induce formation of the subchondral bone and expansion of the calcified cartilage area, eventually leading to degradation of the cartilage tissue.

\section{Introduction}

Osteoarthritis (OA) is the most common chronic degenerative joint disease in orthopedics. It is clinically characterized by varying degrees of joint pain, stiffness, dysfunction and deformity, and ultimately loss of joint function. In the later stages of the disease, it has a non-negligible influence on the quality of life of patients[1, 2]. Risk factors for OA can be broadly classified as systemic, including factors such as age, sex, heredity and ethnicity, or mechanical, including joint structure, alignment, trauma, physical activity, and occupation.[2]. However, for early OA, the main risk factor is age.[3]. In the Framingham study, estimation of the incidence of OA based on the definition of the disease and the age characteristics of the study population[4] revealed a prevalence of radiological knee OA (age 63 to 94 years) estimated at 33\%, with a slightly higher prevalence in women than in men (34\% vs. $31 \%)$. In the same study, the prevalence of symptomatic knee OA was $9.5 \%$, with significantly higher prevalence in women than in men $(11.4 \%$ vs. 6.8\%)[5]. In general, patients do not seek medical care until they experience physical symptoms, although the joint is already severely damaged by this stage. In such cases, partial or complete joint replacement is the only effective treatment, an option that is associated with high medical costs. Excluding the subjective causes, the main objective reasons for this delay in treatment are the unclear pathological mechanism of $\mathrm{OA}$, the lack of accurate and early diagnostic techniques and effective early intervention. With the accelerating growth in the aging population worldwide, OA has become a concern for patients and health workers. 
The pathological changes of OA are characterized by the progressive degradation of articular cartilage and the metabolic dysregulation of subchondral bone, gradually leading to cartilage atrophy, degeneration, and shedding, as well as osteophyte formation and joint edge and surface bone hyperplasia. This tissue destruction is accompanied by subchondral bone remodeling and hypertrophy in addition to varying degrees of synovial hyperplasia, hypertrophy, and fibrosis[6]. Numerous studies have shown that age, sex, immune response, elevated intraosseous pressure, enzyme degradation of cartilage, cytokines, genetic polymorphisms and other factors are related to $\mathrm{OA}$; however, the specific pathological mechanism remains unclear[7, 8][8-10]\{Lories, 2011 \#8;Tchetina, 2010 \#9;Dreier, 2010 \#10\}. Previous research has shown that the interaction between cartilage tissue degradation and subchondral bone metabolism disruption lead to the characteristic pathological changes of $\mathrm{OA}$, although the etiology and pathogenesis of these pathological changes have not been elucidated $[9,10]$. Studies have shown that remodeling of $\mathrm{OA}$ subchondral bone is highly active in a process that involved both bone resorption and formation. Inhibiting subchondral bone remodeling effectively slowed down articular cartilage degeneration, indicating a close relationship between these two processes as well as an important role in the early stages of cartilage degeneration[7]. Previous studies suggest that structural changes in the subchondral bone are closely related to the pain experience by patients with $O A$, and the severity of $O A$ can be expected[11]. However, the current relationship between the changes in subchondral bone and the pathogenesis of $\mathrm{OA}$ as well as the underlying pathological mechanisms are not clear.

Transforming growth factor (TGF $\beta 1$ ) is a pleiotropic cytokine that is closely related to the pathological changes of $O A[12,13]$. During the early stages of joint development, TGF $\beta 1$ is important for the maintenance of a normal chondrocyte phenotype[14]. The articular cartilage performs the biological functions of shock absorption and buffering mechanical stress. Chavez et al.[15] reported that TGF $\beta$ increases the expression of type II collagen (CoIII) and the proteoglycan aggrecan (ACAN) by regulating Smad2/3. In contrast, there are also extensive reports indicating that TGF $\beta 1$ is an important factor in joint destruction. Therefore, the current evidence for the role of TGF $\beta 1$ in the development of OA is contradictory[16]. In many animal models of OA, active TGF $\beta 1$ is expressed at high levels in epiphyseal and subchondral bone calcification [17]. Mesenchymal stem cells (MSCs), also known as pluripotent stem cells, are capable of self-renewal and differentiation into a variety of cells, allowing tissue growth and regeneration[18]. Nestin was identified in neural stem cells and is now used as a marker of bone marrow-derived MSCs[19]. MSCs first differentiate into osteogenic precursor cells and then into osteoblasts. The osteogenic precursor-specific transcription factor, osterix, which was first discovered in mice[20], is one of the most important transcription factors involved in osteoblast differentiation, and its loss leads to a direct loss of bone formation ability. Therefore, osterix expression is used to evaluate osteoblast differentiation. Clinically, TGF 1 is highly expressed in the subchondral bone of OA patients, leading to increased formation of MSC clusters and calluses, and ultimately to the occurrence of OA. Moreover, TGF $\beta 1$ antibody treatment improves bone microstructure, reduces the severity of OA, and delays the progression of joint deterioration[21].Therefore, TGF $\beta 1$ is crucial for the metabolic homeostasis and structural integrity of articular cartilage, although the specific mechanism of action of TGF $\beta 1$ in $O A$ is still controversial. 
Subchondral bone is the main link between cartilage and bone and bone plays an important role in the stress transmission process. Therefore, a role for subchondral bone plays a role in $\mathrm{OA}$ is increasingly being proposed $[22,23]$. In our preliminary study, we found that active TGF $\beta 1$ was highly expressed in the subchondral bone of OA patients, and the reactivity of the patient's chondrocytes to TGF $\beta 1$ was decreased, which was consistent with the changes in TGF $\beta 1$ receptor expression in elderly OA cases. The level of active TGF $\beta 1$ is also elevated in a mouse anterior cruciate ligament rupture OA model (ACLT-OA) and a spontaneous OA guinea pig model. Cui et al.[24]showed that reduced TGF $\beta 1$ expression in the mouse ACLT-OA model impeded articular cartilage degeneration. The subchondral bone undergoes a process of plastic bone and bone remodeling. During osteolysis caused by osteoclasts, TGF- $\beta 1$ induces proliferation of nestin-positive MSCs and transcription factor osterix-positive osteogenic precursor cells, which couples bone remodeling and angiogenesis[25]. These reports indicate that TGF $\beta 1$ plays different roles in the remodeling of subchondral bone and the pathological changes of articular cartilage, although the underlying mechanism requires further clarification.

Clinical OA joint samples are obtained long after the lesions have formed and after a very long period of wear. Animal models of OA offer the advantage that samples can be obtained at different stages during the development of the lesion. Such models provide the opportunity to investigate differences in the microstructure of the subchondral bone at different stages and different degrees of cartilage wear, the relationship between these differences and TGF $\beta 1$ expression and the relationship with OA articular cartilage degeneration and subchondral bone remodeling.

In this study, control normal cartilage specimens and clinical OA specimens were collected to investigate the changes in cartilage and subchondral bone structure, the activity of TGF $\beta 1$ and its correlation with cartilage-degrading enzymes and OA lesions. This information will provide an important basis for the clinical application of TGFB1-targeted therapy for OA.

\section{Methods}

Chemicals and reagents

Antibodies for detection of TGF $\beta 1$, MMP-3, MMP-13, IL-1 $\beta$, PTHrP, Indian hedgehog (IHH), sonic hedgehog $(\mathrm{SHH}), \beta$-catenin, pSmad1, nestin, and osterix were purchased from Abcam Corporation (USA). The QuantiNova SYBR Green PCR Kit (500) was purchased from Qiagen GmbH (Germany). The PCR amplification machine (AG 22331 Hamburg) was purchased from Eppendorf Corporation (Germany). The frozen high-speed microfuge (Thermo Scientific Heraeus Fresco 17) was purchased from Thermo Fisher Scientific (USA). The Modified Safranine O-Fast Green FCF Cartilage Stain kit and SDS-PAGE Kit were purchased from Beijing Solarbio Technology Co., Ltd.

Experimental samples and protocol

Inpatients from the Department of Joint Surgery, the First Affiliated Hospital of Shihezi University Medical College were enrolled into this study from March 2016 to December 2018. Joint samples were obtained 
from 100 patients (48 males and 52 females; average age of $69 \pm 5$ years) with confirmed OA patients undergoing total knee arthroplasty and 20 patients with amputation due to trauma (see Appendix for inclusion and exclusion criteria).

All patients signed informed consent prior to participating in the study. The study was approved by the Ethics Committee of the First Affiliated Hospital of the Medical College.

Decalcification of joint samples was carried out in $10 \%$ EDTA at $-80^{\circ} \mathrm{C}$. All the joints of one side of the tibial plateau were divided into a mild (normal cartilage), moderate (cartilage wear) and severe (cartilage exfoliation) according to the degree of lesions; the mild group was used as the control for statistical analysis. According to the Kellgren and Lawrence (K-L) classification [26], of the 100 patients, eight (8\%) were grade $2 \mathrm{OA}, 62(62 \%)$ were grade $3 \mathrm{OA}$, and $30(30 \%)$ were grade $4 \mathrm{OA}$.

In the control group, tibial plateau samples were collected from 20 healthy joints ( 12 males and 8 females; average age $56 \pm 4$ years) obtained from patients who had undergone amputation due to trauma and died of acute disease consent at the Department of Trauma of the First Affiliated Hospital of Shihezi University and the Department of Trauma of Shihezi People's Hospital China. The control group was The tibial plateau did not have any form of joint disease.

Histological examination

The knee tibial plateau tissue sections were dewaxed in xylene and then hydrated in a series of graded ethanol solutions. The sections were placed in $0.4 \%$ pepsin and fixed at $37^{\circ} \mathrm{C}$ for $30 \mathrm{~min}$. After washing three times with PBS, sections were immersed in $3 \%$ hydrogen peroxide for $30 \mathrm{~min}$, washed again and then incubated in $5 \%$ fetal bovine serum blocking solution for $30 \mathrm{~min}$. The sections were then placed in hematoxylin solution for $30 \mathrm{~s}$, acidified for $3-5 \mathrm{~s}$, and rinsed with tap water until no color, tap water returned to blue for $10 \mathrm{~min}$. Subsequently, sections were washed three times with PBS followed by $95 \%$ alcohol before dehydration in anhydrous ethanol, and then immersed in xylene to render the tissue transparent. Sections were sealed with optical resin.

Masson's trichrome staining

The knee tibial plateau tissue sections were dewaxed in xylene and then hydrated in a series of graded ethanol solutions. Subsequently, $50 \mu \mathrm{L}$ of Lichunhong acid magenta dye solution, phosphomolybdic acid solution and aniline blue dye solution were added for $5 \mathrm{~min}$, and the sections were washed with $1 \%$ glacial acetic acid aqueous solution. Subsequently, sections were washed three times with PBS followed by $95 \%$ alcohol before dehydration in anhydrous ethanol, and then immersed in xylene to render the tissue transparent. Sections were sealed with optical resin.

Modified Safranin O-Fast green staining

The knee tibial plateau tissue sections were dewaxed in xylene and then hydrated in a series of graded ethanol solutions. Sections were immersed in freshly prepared Weigert dye solution for 3-5 min, washed 
with water and then immersed in acidic differentiation solution for $15 \mathrm{~s}$. After washing in distilled water for $10 \mathrm{~min}$, sections were immersed in Safranin 0 stain for $5 \mathrm{~min}$. Subsequently, sections were washed three times with PBS followed by $95 \%$ alcohol before dehydration in anhydrous ethanol, and then immersed in xylene to render the tissue transparent. Sections were sealed with optical resin.

\section{Immunohistochemical staining}

The knee tibial plateau tissue sections were dewaxed in xylene and then hydrated in a graded series of ethanol solutions. The sections were placed in $0.4 \%$ pepsin and fixed at $37^{\circ} \mathrm{C}$ for $30 \mathrm{~min}$. After washing three times with PBS, sections were immersed in $3 \%$ hydrogen peroxide for $30 \mathrm{~min}$, washed again and then incubated in $5 \%$ fetal bovine serum blocking solution for $30 \mathrm{~min}$. Sections were then incubated overnight at $4^{\circ} \mathrm{C}$ with primary detection antibodies (TGF $\beta 1$, 1:200; MMP-3, 1:200, MMP-13, 1:50; IL-1 $\beta$, 1:200; PTHrP, 1:25; IHH, 1:50; SHH, 1:100; $\beta$-catenin, 1:100; nestin, 1:500; Osterix, 1:20; and pSmad1, 1:50). After incubation at room temperature for $30 \mathrm{~min}$, sections were rinsed three times and incubated with the secondary antibody at $37^{\circ} \mathrm{C}$ for a further $30 \mathrm{~min}$. DAB color development was monitored under an optical microscope to control and the reaction was stopped rinsing with tap water. The sections were then placed in hematoxylin solution for $30 \mathrm{~s}$, acidified in acid alcohol for 3-5 seconds, rinsed in tap water and then returned to blue for $10 \mathrm{~min}$. Subsequently, sections were washed three times with PBS followed by $95 \%$ alcohol before dehydration in anhydrous ethanol, and then immersed in xylene to render the tissue transparent. Sections were sealed with optical resin.

Immunohistochemical staining (percentage positive cells and staining intensity) was scored quantitatively in six fields randomly selected randomly under the microscope. The percentage of positive cells was scored as follows: $0,<5 \% ; 1,6 \%-25 \% ; 2,26 \%-50 \% ; 3,51 \%-75 \%$; and $4,76 \%-100 \%$. Staining intensity was scored as follows: 0 , no staining; 1 , light brownish yellow; 2 , brownish yellow; and 3 , tan. The final score for each section was calculated by multiplying the scores for percentage of positive cells and staining intensity.

Western blot analysis

The hypoglossal bone tissue of the tibial plateau was ground under liquid nitrogen and then incubated overnight at $4{ }^{\circ} \mathrm{C}$ in high-efficiency lysate RIPA buffer and the PMSF protease inhibitor. The protein concentration was determined by ultraviolet spectrophotometry (A280). 1/4 of a loading buffer was added to the EP tube for 10 minutes to be used at $-80^{\circ} \mathrm{C}$. The protein sample was added to the loading buffer, electrophoresed on an SDS polyacrylamide gel. For TGF $\beta 1$ and osterix detection, proteins were transferred to the PVDF membrane using a semi-dry method, whereas a wet-transfer method was used for detection of nestin. Membranes were then blocked at room temperature for $2 \mathrm{~h}$, washed three times with TBST and incubated overnight with the primary detection antibodies (TGF $\beta 1$, nestin, osterix antibodies, 1:1,000; $\beta$-actin antibody, 1:20,000). After washing three times with TBST, membranes with the secondary antibody for $2 \mathrm{~h}$ at room temperature. Protein immunoreactivity was visualized using XXXX. Image-Pro Plus software was used to analyze the grayscale values of the protein bands. 
Total RNA was extracted from the tibial plateau using Qiagen kit and TRIzol reagent (Invitrogen) and reverse transcribed into cDNA using SuperScript First-Strand Synthesis System (Invitrogen). Using cDNA as a template, SYBR GreenMaster Mix (Qiagen) was used for RT-PCR amplification of target genes (TGF $\beta 1$, MMP-3, MMP-13 and IL-1 $\beta$ ) and internal control ( $\beta$-actin) using the following PCR parameters: pre-denaturation at $95^{\circ} \mathrm{C}$ for $2 \mathrm{~min}$; denaturation at $95^{\circ} \mathrm{C}$ for $30 \mathrm{~s}$; extension at $60^{\circ} \mathrm{C}$ for $30 \mathrm{~s}$ (40 cycles). The primer sequences are shown in Table 1. Relative gene expression was analyzed using the $2-\Delta \Delta \mathrm{Ct}$ method.

Micro-CT joint imaging

The isolated tibia was imaged using the GEHC MicroView. The resolution was adjusted to $9 \mathrm{~mm}$ for scanning, and the 3-dimensional (3D) image was then reconstructed. After 3D reconstruction, the region of interest (ROI) of the subchondral bone in the human tibial plateau was selected. The ROI included all trabecular bone surrounded by a growth plate and a distal tibia (1-4 mm). For each ROI, we measured bone mineral density (BMD), bone volume fraction (BV/TV), trabecular thickness (Tb.Th), trabecular bone number (Tb.N), trabecular bone spacing (Tb.Sp), trabecular surface area/skeleton (BS/BV).

Statistical analysis

All statistical analyses were performed using SPSS 20.0 (IBM Corp, Armonk, NY, USA). Differences between groups was evaluated by one-way ANOVA and chi-squared tests. P-values $<0.05$ were considered to indicate statistical significance.

\section{Results}

Visual observation of specimen morphology

By visually observing the specimen, it was found that the articular cartilage on the lateral side of the tibial plateau was lightly worn, and the cartilage surface was relatively intact. No cartilage sclerosis, bare subchondral bone or osteophyte formation were found. Compared with the medial and lateral aspects of the tibial plateau, the surface of the medial platform was uneven. Furthermore, the area of the weightbearing area of the joint and the area with severe wear had complete signs of cartilage exfoliation. The surface showed osteophyte hyperplasia, and bare cartilage and subchondral bone calcification were visible. (Figure 2-1)

Histological evaluation of cartilage and subchondral bone

As shown in Figure 2-2, histological examination following Modified Safranin 0-Fast green and Masson's trichrome staining showed thicker cartilage in the cartilage wear group compared to that in the cartilage intact group, with disordered chondrocyte arrangement. In addition, the subchondral bone thickness was increased and the cartilage surface was uneven with obvious cracks. In the cartilage exfoliation and 
cartilage intact groups, almost completely disappeared than the hyaline cartilage. The subchondral bone was exposed and deformed obviously. The calcified cartilage thickening was obviously exposed, and the bone cell and bone structure in the subchondral bone area decreased although the accumulation of lipid droplets was increased.

Increased TGF $\beta 1$ expression in the subchondral bone correlated positively with the degree of degeneration

Immunohistochemical analysis showed low levels of TGF $\beta 1$ protein in the control group, whereas the levels were significantly higher in the cartilage and subchondral bone of the moderate and severe OA patients $(X 2=18.486 a, P<0.05, n=69)$, especially in the subchondral bone near the cartilage area (Figure 2-3). Western blot analysis showed that TGF 31 protein expression in the subchondral bone of the OA group was significantly increased compared with that in the control group. However, there were no significant differences in TGF $\beta 1$ protein expression between the different degrees of wear (Figure 2-3). RTPCR showed higher levels of TGF $\beta 1$ mRNA expression in subchondral bone in the moderate and severe groups than those in the control group (Figure 2-3).

Elevated expression of cartilage-degrading enzymes in cartilage and subchondral bone

Immunohistochemical analysis showed significantly $(P<0.05, n=69)$ higher expression of MMP3, MMP13, IL-1 $\beta, P T H r P, I H H, S H H, \beta-c a t e n i n$ and pSmad1 ( $\chi 2$ = 20.653a, 22.951a, 36.192a, 30.212a, 35.558a, $11.500 a, 31.072 a$ and $11.072 a$, respectively) in cartilage and subchondral bone in moderate and severe OA patients compared with that in the control group (Figure 2-4). RT-PCR also showed that expression of MMP3, MMP-13 and IL-1 $\beta$ mRNA in the subchondral bone of the articular cartilage destruction area in moderate and severe OA patients was higher than that in the control group (Figure 2-4).

TGF $\beta 1$, nestin and osterix expression patterns reflected differences in subchondral bone degeneration Immunohistochemical analysis showed that, compared with the low levels of TGF $\beta 1$, nestin and osterix proteins expressed in the subchondral bone in the control group, significantly $(P<0.05, n=69)$ higher levels of all three proteins were expressed in the subchondral bone of the moderate and severe $\mathrm{OA}$ patients ( $\mathrm{X} 2=18.486 \mathrm{a}, 11.523 \mathrm{a}$ and $17.875 \mathrm{a}$, respectively) (Figure 2-5A). Western blot analysis also showed that the expression of TGF $\beta 1$, nestin and osterix proteins in the subchondral bone of the cartilage destruction group was significantly increased compared with that in the control group (Figure 2-5B).

Micro-CT imaging of the extent of subchondral bone thickening

The micro-CT imaging results of the cartilage exfoliation area and the of subchondral bone in the normal control group are shown in Table 2-1 and Figure 2-6. The ratio of BV/TV $(0.8066 \pm 0.06928)$ in the OA group was significantly higher than that in the control group $(0.0647 \pm 0.02992)(P<0.001)$. In accordance with this change, the Tb.N $(3.5831 \pm 0.93732)$ and Tb.Th $(0.2675 \pm 0.06986)$ values in OA group were significantly higher than those in control group $(1.2938 \pm 0.5904)(P<0.05$ and $P<0.001$, respectively), showing that the thickness of trabecular bone and number of trabecular bone cells were increased 
compared with the control group, which led to an increase in BV/TV. The BMD of the OA group (549.4933 \pm 70.79334$)$ was significantly higher than that of the control group $(25.4986 \pm 12.19363)(P<$ 0.001). These observations demonstrated that, in the cartilage exfoliation area, the microstructure of the subchondral bone is seriously disordered and accompanied by cellular proliferation.

The micro-CT imaging results of the cartilage wear zone and the normal control subchondral bone are shown in Table 2-2 and Figure 2-6. The ratio of BV/TV $(0.7246 \pm 0.12835)$ in the OA group was significantly higher than that in the control group $(0.0647 \pm 0.02992)(P<0.001)$. In accordance with this change, the Tb.N $(2.8204 \pm 1.44650)$ and Tb.Th $(0.1808 \pm 0.05915)$ values in OA group were significantly higher than those in control group $(1.2938 \pm 0.5904)(P<0.05)$. These observations demonstrated that the thickness of trabecular bone and number of trabecular bone cells, which led to an increase in BV/TV. The BMD of the OA group (445.2538 \pm 103.2219$)$ was significantly higher than that of the control group (25.4986 \pm 12.19363$)(P<0.001)$. These observations demonstrated that the microstructure of the subchondral bone in the cartilage wear group is also seriously disordered and accompanied by cellular proliferation. These two comparisons show that the thickness of the subchondral bone increases with the degree of cartilage degeneration.

\section{Discussion}

In 1986, Radin et al.[27] first proposed the role of subchondral bone in the process of cartilage degeneration. Subchondral bone plays an important role in the physiological function of joints, and its metabolic changes have an important influence on the degradation of articular cartilage. Studies have shown that remodeling of $O A$ subchondral bone is a highly active process involving bone resorption and formation. In early $\mathrm{OA}$, the subchondral bone and the trabecular bone became thinner, showing excessive bone resorption. Although the cortical endplate is hardened, there is severe loss of the cancellous bone underneath, and the subchondral bone capsule is enlarged in the weight-bearing area of the joint. By inhibiting remodeling of subchondral bone, articular cartilage degeneration can be significantly delayed. Therefore, subchondral bone remodeling is closely related to the degeneration of articular cartilage, and plays an extremely important role in the initial stage of cartilage degeneration[7].

Accumulating evidence shows that transforming growth factor (TGF $\beta 1$ ) is closely related to the pathological changes of $\mathrm{OA}^{[28,29]}$. In normal joints, TGF $\beta 1$ is involved in the regulation of cartilage growth and metabolism of subchondral bone, and plays a key role in maintaining joint homeostasis. However, the effects and functions of TGF 1 are changed in $O A$, in which the cytokine is involved in the induction of chondrocyte phenotype differentiation, chondrocyte proliferation, and destruction of the extracellular matrix synthesis ${ }^{[30]}$. Subchondral bone callus formation and abnormal bone reconstruction are symptoms of the development of arthritis ${ }^{[31]}$ and important mechanisms responsible for the progression of $\mathrm{OA}^{[32]}$. Studies have shown abnormal elevation of TGF $\beta 1$ in $\mathrm{OA}$ human specimens and various animal models ${ }^{[33,34]}$, which is consistent with the findings of this study. Furthermore, it has been reported that the stimulatory factor TGF $\beta 1$ released from the chondrocytes of damaged joints stimulates the synthesis 
of protein matrix-degrading enzymes ${ }^{[35]}$, leading to degradation of the extracellular matrix (ECM). In this study, we analyzed the expression of TGF $\beta 1$ and the major cartilage-degrading enzymes MMP-3/13 and IL-1 $\beta$ in the OA knee tibia plateau. Our results indicate that the high levels of TGF $\beta 1$ expression promote the synthesis of matrix degrading-enzymes, leading to cartilage degradation. Matrix metalloproteinase MMP3 is a mesenchymal lytic enzyme ${ }^{[36]}$ that degrades the proteoglycans and glycoproteins in the ECM. Studies have shown that MMP3 is highly expressed in OA cartilage, synovium, synovial fluid and peripheral blood ${ }^{[37]}$. Similarly, we found that MMP3 is highly expressed in cartilage and subchondral bone.

Matrix metalloproteinase MMP13, also known as collagenase ${ }^{[38]}$, is the major type II collagen-degrading enzyme and is prominently expressed in the cartilage matrix ${ }^{[39]}$. Studies have confirmed high expression ${ }^{[40]}$ and enhanced activity ${ }^{[41,42]}$ of MMP13 in OA cartilage tissue samples. Furthermore, MMP13 is

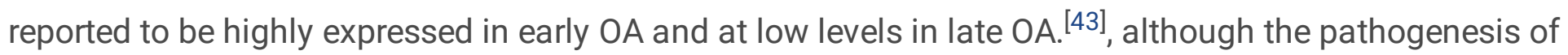
$\mathrm{OA}$ is associated with increased MMP13 expression [44]. These reports are consistent with the results of our study. Although studies of MMP13 expression in the subchondral bone are rare, our results show high MMP13 expression in the subchondral bone.

Interleukin (IL)-1 $\beta$ is an inflammatory mediator that acts as a catabolic agent in arthritis. Inflammation plays a crucial role in the development of $\mathrm{OA}$, and IL- $1 \beta$, which is highly expressed in $\mathrm{OA}$ patients ${ }^{[45]}$, plays an important pro-inflammatory role during inflammatory reactions. It also increases the secretion of major proteolytic enzymes in cartilage, including MMPs and A disintegrin and metalloproteinase with thrombospondin motifs (ADAMT-5) ${ }^{[46]}$. In addition, IL-1 $\beta$ induces NO production, and the enhances cyclooxygenase-2 (COX-2) activity, which ultimately leads to ECM degradation.

PTHrP was first discovered as a cancer-derived hormone, but it has since been shown to be an important factor in the development and maturation of cartilage and bone as well as an important regulator of endochondral bone formation and bone remodeling ${ }^{[47]}$. PTHrP is highly expressed in articular cartilage, and is induced by the lipoprotein receptor-related protein 6 (LRP6) 6 to inhibit the sclerostin SOST, which inhibits bone formation ${ }^{[48]}$. In this study, we show that the percentage of PTHrP-positive cells and expression intensity in cartilage and subchondral bone are increased, further indicating that PTHrP promotes bone formation. PTHrP is produced by chondrocytes to promote the proliferation of adjacent chondrocytes, and can delay its differentiation into hypertrophic chondrocytes. When PTHrP cannot stimulate these cells, hypertrophic chondrocytes secrete $\mathrm{IHH}$, which promotes the proliferation and differentiation of hypertrophic chondrocytes and accelerates the differentiation of adjacent chondrocytes into osteoblasts ${ }^{[49]}$. Accumulating evidence suggests the importance of the $\mathrm{Hh}$ signaling pathway that regulates the cartilage osteogenesis, especially the formation of $\mathrm{IHH}$ and $\mathrm{SHH}$, in the formation of vertebrate bones ${ }^{[50]}$. $\mathrm{IHH}$ is a very important factor in the development of cartilage damage and $\mathrm{OA}$. Previous studies have shown that $\mathrm{IHH}$ is highly expressed in articular cartilage in OA mouse models and human $\mathrm{OA}$ patients and that high expression of $\mathrm{IHH}$ is related to the severity of $\mathrm{OA}^{[51]}$. Our results show 
high expression in both articular cartilage and subchondral bone, indicating that $\mathrm{IHH}$ upregulation is associated with the pathogenesis of OA.

$\mathrm{SHH}$ is a very important factor for embryonic and organ development, and plays an important role in bone formation in bone remodeling, regulating the osteogenic differentiation of bone marrow mesenchymal stem cells. SHH has been shown to be present and highly expressed in various cancers such as bladder cancer ${ }^{[52]}$, lung cancer ${ }^{[53]}$, and thyroid cancer ${ }^{[54]}$; however, there are few studies in osteoarthritis. Our results showed that the expression of SHH protein in the cartilage and subchondral bone of the cartilage wear and cartilage exfoliation groups was significantly increased compared with that in the intact cartilage group $(P<0.05)$. Therefore, $\mathrm{SHH}$ is implicated as a potential influencing factor in the development of OA.

$\beta$-Catenin belongs to the intracellular glycoprotein family and is a key molecule in the classical Wnt pathway. It is widely distributed in the cell membrane, cytoplasm and nucleus and exerts various functions. Matrix metalloproteinases MMPs are highly expressed in articular cartilage of rats and rabbits and are activated by the Wnt/ $\beta$-catenin signaling pathway ${ }^{[55,56]}$. Furthermore, $\beta$-catenin induces high expression of MMP-9, MMP-13 and BMP-2 genes in chondrocytes, which in turn, leads to OA production in mouse knee joints ${ }^{[57]}$. In accordance with previous reports, we show that high levels of $\beta$-catenin expression in the subchondral bone in OA patients. Typically, TGF- $\beta / S m a d$ signals through two main pathways; ALK5/Smad2/Smad3 and ALK1/SMAD1/SMAD5/SMAD. The TGFB/ALK5/Smad2/Smad3 signal transduction pathway inhibits further differentiation of chondrocytes to maintain the normal phenotype $^{[14]}$. The TGF $\beta / A L K 1 / S M A D 1 / S M A D 5 / S M A D 8$ signal transduction pathway induces the synthesis of MMP13, leading to cartilage matrix degradation, hypertrophy of chondrocytes and vascularization and calcification of articular cartilage ${ }^{[58]}$. Davidson ${ }^{[59]}$ reported that the ALK1/ALK5 ratio was elevated in damaged articular cartilage in OA mice. Peter $\mathrm{M}^{[60]}$ demonstrated that ALK 1 predominates and activates SMAD1/5/8 in OA in vitro, and the level of pSmad 1 is increased in chondrocytes. Similarly, in the present study, semi-quantitative immunohistochemical staining revealed a high expression of phosphorylated Smad1 in the cartilage and subchondral bone of the cartilagedestroyed group compared with that the intact cartilage group.

Bone remodeling is accomplished through tightly regulated coordination of bone formation and resorption mediated by osteoblasts that deposit calcified bone matrix and osteoclasts that resorb bone $\mathrm{e}^{[61}$, 62]. These processes do at specific anatomical sites and follow a well-defined sequence of events known as the bone remodeling cycle ${ }^{[63]}$. Studies have shown that active TGF $\beta 1$ acts as a pro-migratory factor involved in tissue damage and remodeling to induce MSC migration to normal and pathological tissues for repair and remodeling ${ }^{[64]}$. It has also been reported that in the process of osteolysis mediated by osteoclasts, one or multiple factors are released from the bone matrix, including transforming growth factor TGF $\beta 1$, which in the active form, functions as a coupling factor to induce migration of bone marrow MSCs to bone for the formation of new bone; however, excessive TGF $\beta 1$ activity leads to abnormal remodeling of subchondral bone ${ }^{[65]}$. In the pre-experiment, TRAP staining in the ACLT mouse 
model revealed an obvious increase in osteoclasts, and immunohistochemistry showed that increased levels pSmad2/3 (a downstream factor of TGF $\beta 1$ ), demonstrating that osteoclasts caused increased bone resorption and activated TGF $\beta 1$. Furthermore, immunohistochemistry showed changes in the number and location of nestin-positive (MSCs) and osterix-positive (osteogenesis precursor) cells, indicating that active TGF $\beta 1$ aggregates MSCs and osteogenic precursor cells to cause bone formation of the subchondral bone. These observations are is consistent with our findings in OA patients. In addition, in the pre-experimental ACLT mouse model, the mechanism underlying the role of TGF $\beta 1$ in cartilage degeneration was verified. After injection of the appropriate concentration $(1 \mathrm{mg} / \mathrm{kg})$ of TGFBR1 inhibitor in the ACLT model, the thickness of calcified articular cartilage decreased, and the Mankin score decreased significantly. Flow cytometric analysis showed a significant reduction in nestin-positive MSCs and osterix-positive osteogenesis precursor cells. It is well known that subchondral bone undergoes bone remodeling in the development of OA. Osteoclasts cause osteolysis, and chondrocytes release TGF $\beta 1$ to induce proliferation and aggregation of nestin-positive MSCs and transcription factor osterix-positive osteogenic precursor cells. Eventually, unconjugated bone remodeling occurs, and hyperplastic changes in the subchondral bone structure lead to uneven stress and degeneration of the articular cartilage. This is consistent with our findings showing that, compared with the intact cartilage group, the expression of TGF $\beta 1$ as well as nestin-positive and osterix-positive cells in the subchondral bone damaged by the cartilage area was increased. Moreover, the increased expression of PTHrP, IHH and SHH and the abnormal proliferation of subchondral bone revealed by micro-CT imaging demonstrated abnormal remodeling of subchondral bone. This study and previous studies show that high TGF $\beta 1$ activity is associated with abnormal remodeling of subchondral bone. Therefore, controlling the activity of TGF $\beta 1$ in cartilage and subchondral bone may represent a new target for $\mathrm{OA}$ therapies.

Some limitations of this study should be noted. First, relatively few tibial plateau specimens representing each cycle of OA in patients were available because knee replacement is performed late OA. Furthermore, a longitudinal study of cartilage and subchondral bone is required. Therefore, our findings may not reflect the subchondral bone pathology during disease progression. However, the advancement of imaging technology, such as micro-CT, may provide opportunities for non-invasive evaluation of patients that will facilitate longitudinal studies to identify new targets for OA diagnosis and treatment.

\section{Conclusions}

The findings of the present study show that abnormal changes in cartilage and subchondral bone are associated with high expression of TGF- $\beta 1$. Furthermore, high levels of active TGF- $\beta 1$ are involved in the synthesis of cartilage-degrading enzymes and cartilage degradation in clinical OA samples. In middle and late stage OA patients, the thickness, number and bone volume fraction of the trabecular bone in the subchondral bone are increased, while the trabecular bone spacing is decreased, and the subchondral bone exhibits abnormal proliferation. Moreover, high levels of active TGF $\beta 1$ are associated with migration and aggregation of nestin-positive MSCs and osterix-positive osteogenic precursor cells. Therefore, regulating the activity of TGF $\beta 1$ in cartilage and subchondral bone is a potential treatment for OA treatment. 


\section{Abbreviations}

\begin{tabular}{|l|l|l|l|}
\hline OA & Osteoarthritis & $\begin{array}{l}\text { Micro- } \\
\text { CT }\end{array}$ & micro computed tomography \\
\hline TGFß1 & $\begin{array}{l}\text { Transforming growth factor } \\
\text { beta 1 }\end{array}$ & BV/TV & bone volume fraction \\
\hline MMP3 & Matrix metalloproteinase3 & Tb/Th & Trabecular thickness \\
\hline MMP- & Matrix metalloproteinase 13 & Tb/N & Trabecular bone number \\
\hline IL-1 $\beta$ & Interleukin-1beta & Tb.Sp & trabecular bone spacing \\
\hline PTHrP & $\begin{array}{l}\text { Parathyroid hormone-related } \\
\text { protein }\end{array}$ & BMD & Bone density \\
\hline IHH & Indian Hedgehog & ECM & extracellular matrix \\
\hline SHH & Sonic Hedgehog & MSCs & Mesenchymal stem cells \\
\hline $\begin{array}{l}\text { RT- } \\
\text { PCR }\end{array}$ & $\begin{array}{l}\text { Real time- } \\
\text { Polymerase Chain Reaction }\end{array}$ & Smad & $\begin{array}{l}\text { drosophila } \\
\text { decapentaplegic }\end{array}$ \\
\hline
\end{tabular}

\section{Declarations}

Ethics approval and consent to participate

Approved by the Ethics Committee of the First Affiliated Hospital of Shihezi University Medical College

Consent for publication $\llbracket$ Not applicable『

The authors claim that none of the material in the paper has been published or is under consideration for publication elsewhere.

Availability of data and materials 
The datasets used and/or analysed during the current study are available from the corresponding author on reasonable request.

Competing interests

The authors declare that they have no competing interests" in this section.

Funding

This work was supported by the National Natural Science Foundations of China (No.81772407)

Authors' contributions

The author PU Peidong performed tissue staining on bone tissue, IH, western-blot, RT-PCR, Micro-CT, and was a major contributor to the writing of manuscripts, F HAN, QY MA, TY MA, WP ZHOU, ZJ ZHU, MY WANG, C WANG, C SHI conducted the collection of the tibial plateau tissue of the knee and helped with the experiment. All authors read and approved the final manuscript.

Acknowledgements $₫$ Not applicable区

\section{References}

[1] AD P, RF W, SA R. Basic science of articular cartilage and osteoarthritis [J]. Clinics in sports medicine, 2005, 24(1): 1-12.

[2] TW O N, PS M, J M. Update on the epidemiology, risk factors and disease outcomes of osteoarthritis [J]. Best practice \& research Clinical rheumatology, 2018, 32(2): 312-26.

[3] ZHANG Y, JORDAN J M. Epidemiology of osteoarthritis [J]. Rheumatic Disease Clinics of North America, 2008, 34(3): 515-29.

[4] PEREIRA D, PELETEIRO B, ARA ${ }^{\circ} \mathrm{JO} \mathrm{J}$, et al. The effect of osteoarthritis definition on prevalence and incidence estimates: a systematic review [J]. Osteoarthritis Cartilage, 2011, 19(11): 1270-85.

[5] FELSON D T, NAIMARK A, ANDERSON J, et al. The prevalence of knee osteoarthritis in the elderly. the Framingham osteoarthritis study [J]. Arthritis \& Rheumatology, 2014, 30(8): 914-8.

[6] RF L. Aging and osteoarthritis [J]. Current opinion in rheumatology, 2011, 23(5): 492-6. 
[7] LORIES R J, LUYTEN F P. The bone-cartilage unit in osteoarthritis [J]. Nature Reviews Rheumatology, 2011, 7(1): 43.

[8] TCHETINA E V. Developmental mechanisms in articular cartilage degradation in osteoarthritis [J]. Arthritis,2011,(2010-12-15), 2010, 2011(2090-1984): 683970.

[9] TCHETINA E V. Developmental mechanisms in articular cartilage degradation in osteoarthritis [J]. Arthritis, 2010, 2011(2090-1984): 683970.

[10] DREIER R. Hypertrophic differentiation of chondrocytes in osteoarthritis: the developmental aspect of degenerative joint disorders [J]. Arthritis Research \& Therapy, 2010, 12(5): 1-11.

[11] ARTHROSCOPY. Knee surgery, sports traumatology, arthroscopy : official journal of the ESSKA [J].

[12] VAN D K P M, MARIE-JOS G, ESMERALDA B D, et al. Age-dependent alteration of TGF- $\beta$ signalling in osteoarthritis [J]. Cell \& Tissue Research, 2012, 347(1): 257-65.

[13] BLANEY DAVIDSON E N, REMST D F, VITTERS E L, et al. Increase in ALK1/ALK5 ratio as a cause for elevated MMP-13 expression in osteoarthritis in humans and mice [J]. Journal of Immunology, 2009, 182(12): 7937-45.

[14] A V C, W M, A G D V, et al. TGFß1-induced SMAD2/3 and SMAD1/5 phosphorylation are both ALK5-kinase-dependent in primary chondrocytes and mediated by TAK1 kinase activity [J]. Arthritis research \& therapy, 2017, 19(1): 112.

[15] RD C, G C, J P, et al. SOX9 protein is stabilized by TGF- $\beta$ and regulates PAPSS2 mRNA expression in chondrocytes [J]. Osteoarthritis and cartilage, 2017, 25(2): 332-40.

[16] FANG J, XU L, LI Y, et al. Roles of TGF-beta 1 signaling in the development of osteoarthritis [J]. Histology \& Histopathology, 2016, 31(11): 11779.

[17] VALDES A M, SPECTOR T D, TAMM A, et al. Genetic variation in the SMAD3 gene is associated with hip and knee osteoarthritis [J]. Arthritis \& Rheumatism, 2014, 62(8): 2347-52.

[18] $P B, X C, P S F$, et al. The meaning, the sense and the significance: translating the science of mesenchymal stem cells into medicine [J]. Nature medicine, 2013, 19(1): 35-42.

[19] S M-F, TV M, F F, et al. Mesenchymal and haematopoietic stem cells form a unique bone marrow niche [J]. Nature, 2010, 466(7308): 829-34.

[20] $\mathrm{K} \mathrm{N}, \mathrm{X} \mathrm{Z}, \mathrm{G} \mathrm{K}$, et al. The novel zinc finger-containing transcription factor osterix is required for osteoblast differentiation and bone formation [J]. Cell, 2002, 108(1): 17-29.

[21] ZHEN G, WEN C, JIA X, et al. Inhibition of TGF-[beta] signaling in mesenchymal stem cells of subchondral bone attenuates osteoarthritis [J]. Nature Medicine, 2016, 19(6): 704-12. 
[22] SHARKEY P F, COHEN S B, LEINBERRY C F, et al. Subchondral bone marrow lesions associated with knee osteoarthritis [J]. American Journal of Orthopedics, 2012, 41(9): 413-7.

[23] HENROTIN Y, PESESSE L, SANCHEZ C. Subchondral bone and osteoarthritis: biological and cellular aspects [J]. Osteoporosis International, 2012, 23(8): 847-51.

[24] CUI Z, CRANE J, XIE H, et al. Halofuginone attenuates osteoarthritis by inhibition of TGF- $\beta$ activity and $\mathrm{H}$-type vessel formation in subchondral bone [J]. Annals of the Rheumatic Diseases, 2016, 75(9): 1714-21.

[25] KEYAK J H. Relationships between femoral fracture loads for two load configurations [J]. Journal of Biomechanics, 2000, 33(4): 499-502.

[26] KELLGREN J H, LAWRENCE J S. Radiological assessment of osteo-arthrosis [J]. Ann Rheum Dis, 1957, 16(4): 494-502.

[27] RADIN E L, ROSE R M. Role of subchondral bone in the initiation and progression of cartilage damage [J]. Clin Orthop Relat Res, 1986, 213(213): 34-40.

[28] KRAAN P M, VAN DER, MARIE-JOS G, ESMERALDA B D, et al. Age-dependent alteration of TGF- $\beta$ signalling in osteoarthritis [J]. Cell \& Tissue Research, 2012, 347(1): 257-65.

[29] DAVIDSON E N, BLANEY, REMST D F G, VITTERS E L, et al. Increase in ALK1/ALK5 ratio as a cause for elevated MMP-13 expression in osteoarthritis in humans and mice [J]. Journal of Immunology, 2009, 182(12): 7937-45.

[30] SHEN J, LI S, CHEN D. TGF- $\beta$ signaling and the development of osteoarthritis [J]. Bone Research, 2014, 2(2): 73-9.

[31] CRANE J L, XU C. Bone marrow mesenchymal stem cells and TGF- $\beta$ signaling in bone remodeling [J]. Journal of Clinical Investigation, 2014, 124(2): 466-72.

[32] YUAN X L, MENG H Y, WANG Y C, et al. Bone-cartilage interface crosstalk in osteoarthritis: potential pathways and future therapeutic strategies [J]. Osteoarthritis \& Cartilage, 2014, 22(8): 1077-89.

[33] ZHEN G, WEN C, JIA X, et al. Inhibition of TGF- $\beta$ signaling in subchondral bone mesenchymal stem cells attenuates osteoarthritis [J]. Nature Medicine, 2013, 19(6): 704-12.

[34] WANG W, LI C, PANG L, et al. Mesenchymal stem cells recruited by active TGF $\beta$ contribute to osteogenic vascular calcification [J]. Stem Cells \& Development, 2014, 23(12): 1392-404.

[35] SHEN J, LI J, WANG B, et al. Deletion of the Transforming Growth Factor $\beta$ Receptor Type II Gene in Articular Chondrocytes Leads to a Progressive Osteoarthritis-like Phenotype in Mice [J]. Arthritis \& Rheumatism, 2013, 65(12): 3107-19. 
[36] GUEDERS M M, FOIDART J M, NOEL A, et al. Matrix metalloproteinases (MMPs) and tissue inhibitors of MMPs in the respiratory tract: Potential implications in asthma and other lung diseases [J]. European Journal of Pharmacology, 2006, 533(1-3): 133-44.

[37] PENGAS I, ELDRIDGE S, ASSIOTIS A, et al. MMP-3 in the peripheral serum as a biomarker of knee osteoarthritis, 40 years after open total knee meniscectomy [J]. Journal of Experimental Orthopaedics, 2018, 5(1): 21.

[38] BURRAGE P S, MIX K S, BRINCKERHOFF C E. Matrix metalloproteinases: role in arthritis [J]. Front Biosci, 2006, 11(1): 529-43.

[39] PENGCUI L, JIN D, XIAOCHUN W, et al. Blockade of hypoxia-induced CXCR4 with AMD3100 inhibits production of OA-associated catabolic mediators IL-1 $\beta$ and MMP-13 [J]. Molecular Medicine Reports, 2016, 14(2): 1475-82.

[40] WANG M, SAMPSON E R, JIN H, et al. MMP13 is a critical target gene during the progression of osteoarthritis [J]. Arthritis Res Ther, 2013, 15(1): R5.

[41] LIM N H, MEINJOHANNS E, MELDAL M, et al. In vivo imaging of MMP-13 activity in the murine destabilised medial meniscus surgical model of osteoarthritis [J]. Osteoarthritis \& Cartilage, 2014, 22(6): 862-8.

[42] LI H, WANG D, YUAN Y, et al. New insights on the MMP-13 regulatory network in the pathogenesis of early osteoarthritis [J]. Arthritis Research \& Therapy, 2017, 19(1): 248.

[43] TOMOO S, KOJI K, SATOSHI Y, et al. Comparative analysis of gene expression profiles in intact and damaged regions of human osteoarthritic cartilage [J]. Arthritis and rheumatism, 2010, 54(3): 808-17.

[44] CHEN Y T, HOU C H, HOU S M, et al. The Effects of Amphiregulin Induced MMP-13 Production in Human Osteoarthritis Synovial Fibroblast [J]. Mediators Inflamm, 2014, 2014(6): 759028.

[45] HUANG X, PAN Q, MAO Z, et al. Kaempferol inhibits interleukin-1 $\beta$ stimulated matrix metalloproteinases by suppressing the MAPK-associated ERK and P38 signaling pathways [J]. Molecular Medicine Reports, 2018,

[46] FAN Z, S 9DER S, OEHLER S, et al. Activation of interleukin-1 signaling cascades in normal and osteoarthritic articular cartilage [J]. American Journal of Pathology, 2007, 171(3): 938-46.

[47] MARTIN T J. Parathyroid Hormone-Related Protein, Its Regulation of Cartilage and Bone Development, and Role in Treating Bone Diseases [J]. Physiological reviews, 2016, 96(3): 831-71.

[48] LI C, WANG W, XIE L, et al. Lipoprotein receptor-related protein 6 is required for parathyroid hormone-induced Sost suppression [J]. Annals of the New York Academy of Sciences, 2016, 1364(1): 6273. 
[49] MAES C, KRONENBERG H M. Bone development and remodeling [J]. Bioessays News \& Reviews in Molecular Cellular \& Developmental Biology, 2014, 6(4): 171-5.

[50] A P, L C, A N, et al. A review of hedgehog signaling in cranial bone development [J]. Frontiers in physiology, 2013, 4(undefined): 61.

[51] JINGMING Z, QIAN C, BEATE L, et al. Disrupting the Indian hedgehog signaling pathway in vivo attenuates surgically induced osteoarthritis progression in Col2a1-CreERT2; Ihhfl/fl mice [J]. Arthritis Research \& Therapy, 2014, 16(1): R11.

[52] K S, A L, C Z, et al. Hedgehog signaling restrains bladder cancer progression by eliciting stromal production of urothelial differentiation factors [J]. Cancer cell, 2014, 26(4): 521-33.

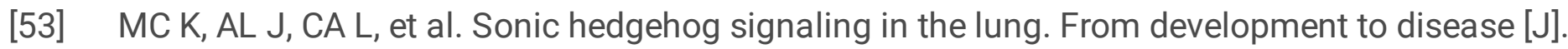
American journal of respiratory cell and molecular biology, 2015, 52(1): 1-13.

[54] X X, Y L, Y L, et al. Sonic Hedgehog Signaling in Thyroid Cancer [J]. Frontiers in endocrinology, 2017, 8(undefined): 284.

[55] R Y, T Y, JA W, et al. Wnt/beta-catenin and retinoic acid receptor signaling pathways interact to regulate chondrocyte function and matrix turnover [J]. The Journal of biological chemistry, 2010, 285(1): 317-27.

[56] T Y, T O, T K, et al. Wnt/beta-catenin signaling stimulates matrix catabolic genes and activity in articular chondrocytes: its possible role in joint degeneration [J]. Laboratory investigation; a journal of technical methods and pathology, 2008, 88(3): 264-74.

[57] M Z, D T, Q W, et al. Activation of beta-catenin signaling in articular chondrocytes leads to osteoarthritis-like phenotype in adult beta-catenin conditional activation mice [J]. Journal of bone and mineral research : the official journal of the American Society for Bone and Mineral Research, 2009, 24(1): $12-21$.

[58] J S, J L, B W, et al. Deletion of the transforming growth factor $\beta$ receptor type II gene in articular chondrocytes leads to a progressive osteoarthritis-like phenotype in mice [J]. Arthritis and rheumatism, 2013, 65(12): 3107-19.

[59] EN B D, DF R, EL V, et al. Increase in ALK1/ALK5 ratio as a cause for elevated MMP-13 expression in osteoarthritis in humans and mice [J]. Journal of immunology (Baltimore, Md : 1950), 2009, 182(12): 7937-45.

[60] PM V D K, MJ G, E B D, et al. Age-dependent alteration of TGF- $\beta$ signalling in osteoarthritis [J]. Cell and tissue research, 2012, 347(1): 257-65.

[61] ZAIDI M. Skeletal remodeling in health and disease [J]. Nature Medicine, 2007, 13(7): 791-801. 
[62] MUNDY G R, FLORENT E. Boning up on ephrin signaling [J]. Cell, 2006, 126(3): 441-3.

[63] HADJIDAKIS D J, ANDROULAKIS I I. Bone Remodeling [J]. Annals of the New York Academy of Sciences, 2006, 1092(1): 385-96.

[64] CRANE J L, XIAN L, CAO X. Role of TGF- $\beta$ Signaling in Coupling Bone Remodeling [J]. Methods in Molecular Biology, 2016, 1344(287.

[65] TANG Y, WU X W. TGF-beta1-induced migration of bone mesenchymal stem cells couples bone resorption with formation [J]. Nature Medicine, 2009, 15(7): 757-65.

\section{Tables}

\section{Table 1 Primer sequences}

\begin{tabular}{lll}
\hline Gene & Primer sequence (5'-3') & Product (bp) \\
\hline TGFß1 & F: CTGTACATTGACTTCCGCAAG & 109 \\
& R: TGTCCAGGCTCCAAATGTAG & \\
MMP3 & F: TACCCACTCTATCACTCACTCA & 276 \\
& R: CAAATGCAATTCAGGTTCAAGC & \\
MMP13 & F: CACTTTATGCTTCCTGATGACG & 95 \\
& R: TCTGGCGTTTTTGGATGTTTAG & \\
IL-13 & F: GCCAGTGAAATGATGGCTTATT & 85 \\
& R: AGGAGCACTTCATCTGTTTAGG & \\
Actin & F: CGTAAAGACCTCTATGCCAACA & 201 \\
& R: AGCCACCAATCCACACACAGAG & \\
\hline
\end{tabular}

1.Table 2-1 Comparison of subchondral bone microstructure in the cartilage exfoliation and control groups by micro-computed tomography imaging

Parameter Cartilage exfoliation group Control group $P$

BV/TV $\quad 0.8066 \pm 0.06928 \quad 0.0647 \pm 0.02992<0.001$

$\begin{array}{lll}\text { Tb.Th } & 0.2675 \pm 0.06986 & 0.0499 \pm 0,01069 \quad<0.001\end{array}$ 
Tb.N

$$
3.5831 \pm 0.93732
$$

$1.2938 \pm 0.5904$

0.023

Tb.Sp

$$
0.0529 \pm 0.00767
$$

$0.8248 \pm 0.34304$

0.018

BMD

$549.4933 \pm 70.79334$

$25.4986 \pm 12.19363$

$<0.001$

Bold indicates statistically significant difference.

2. Table 2-2 Comparison of subchondral bone microstructure in the cartilage wear and control groups

$\begin{array}{llll}\text { Parameter } & \text { Cartilage wear group } & \text { Control group } & P \\ \text { BV/TV } & 0.7246 \pm 0.12835 & 0.0647 \pm 0.02992 & <0.001 \\ \text { Tb.Th } & 0.1808 \pm 0.05915 & 0.0499 \pm 0.01069 & \mathbf{0 . 0 2 0} \\ \text { Tb.N } & 2.8204 \pm 1.44650 & 1.2938 \pm 0.5904 & \mathbf{0 . 0 1 4} \\ \text { Tb.Sp } & 0.0528 \pm 0.01088 & 0.8248 \pm 0.34304 & \mathbf{0 . 0 1 8} \\ \text { BMD } & 445.2538 \pm 103.2219 & 25.4986 \pm 12.19363 & <0.001\end{array}$

Bold indicates statistically significant difference.

\section{Appendix}

\section{Inclusion criteria}

The inclusion criteria were based on the diagnostic criteria for knee osteoarthritis developed by the International Osteoarthritis Research Association in 2014.

(1) The patient has a feeling of pain in the knee joint and has felt pain for most of the past month.

(2) In the medical examinations, $X$-ray imaging is characterized by narrowing and asymmetry of the joint space, sclerosis of the articular cartilage, and the presence of osteophytes. A cystic change can occur under the hardened articular cartilage. 
(3) Patients must undergo two joint fluid examinations to rule out inflammatory arthritis. The laboratory examination of the joint fluid must meet the OA standard: clear joint fluid, normal viscosity, and yellowish color. Inflammatory indicators such as erythrocyte sedimentation rate (ESR) and C-reactive protein are in the normal range.

(4) The activity of the knee joint can be basically maintained, and there is no manifestation of joint rigidity.

(5) Patients aged over 40 years.

(6) Audible of palpable bone rubbing when the joint is active.

The KOA diagnosis requires that $1+2,1+3+5+6$, or $1+4+5+6$ of the above criteria are met.

\section{Exclusion criteria}

Patients with OA who have a history of knee trauma, other forms of arthritis, metabolic bone disease, bone tumors, or drugs that affect bone remodeling were excluded. Not enough subchondral bone was included. The OA tibial plateau (the total thickness of the subchondral bone plate and subchondral trabecular bone $<5 \mathrm{~mm}$ ) was excluded from the study

\section{Figures}

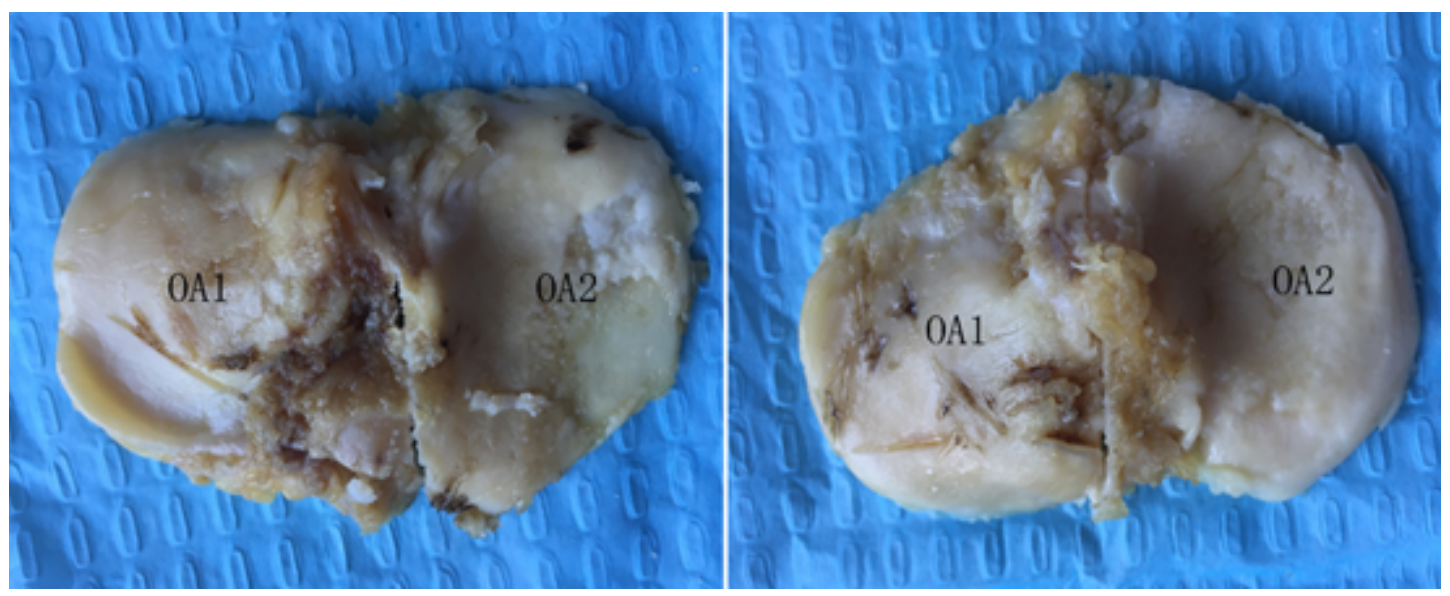

\section{Figure 1}

General view of the tibial plateau. OA1 and OA2 are the lateral and medial sides of the tibial plateau, respectively. 

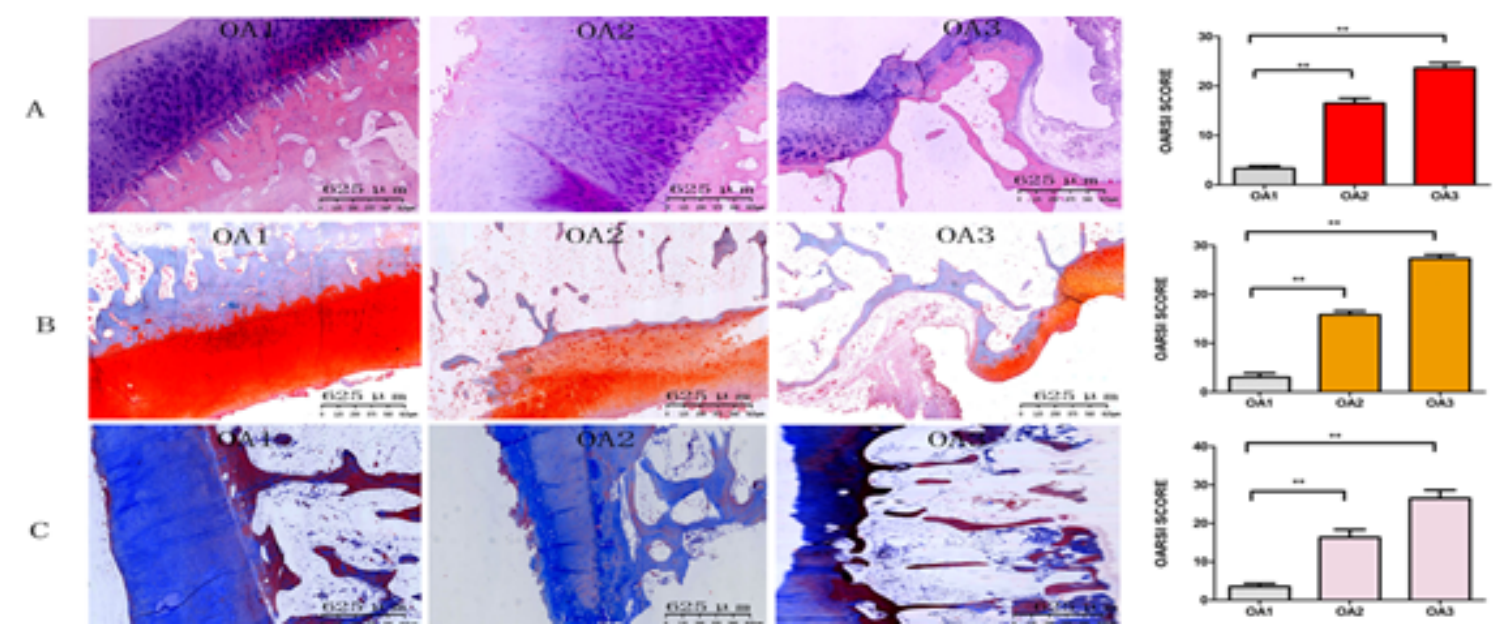

Figure 2

Histological analysis of cartilage integrity and subchondral bone changes. (A) HE staining; (B) Modified Safranin O-Fast green staining; and (C) Masson's trichrome staining. OA1 is the control group $(n=10)$, OA2 is the cartilage wear group $(n=10)$, and OA3 is the cartilage exfoliation group $(n=10)$. Scale bar $=$ $625 \mu \mathrm{m}$. Analysis was performed using the histologic scoring system recommended by the Osteoarthritis Research Society International (OARSI). Data represent the mean \pm SD. ** Indicates statistical significance $(P<0.05)$.

A
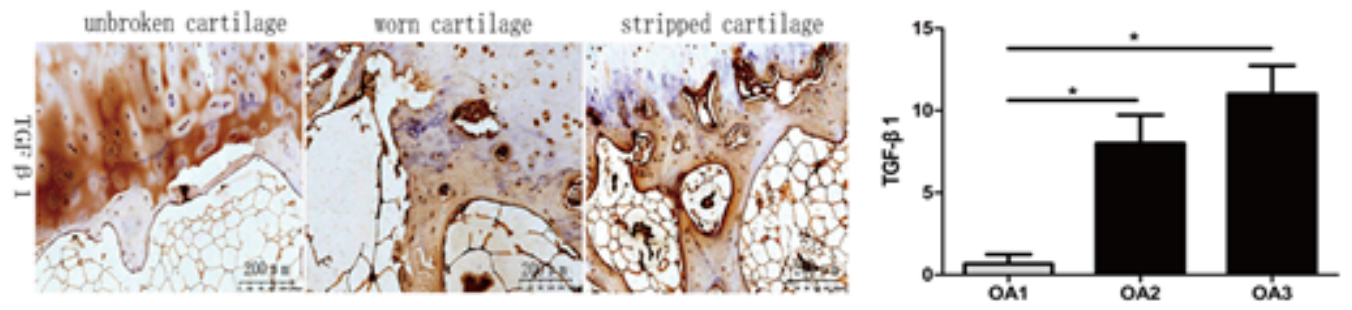

B

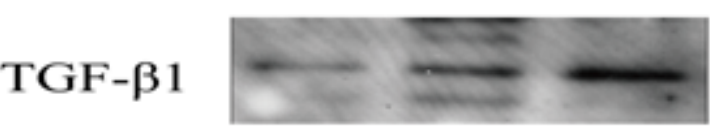

GAPDH
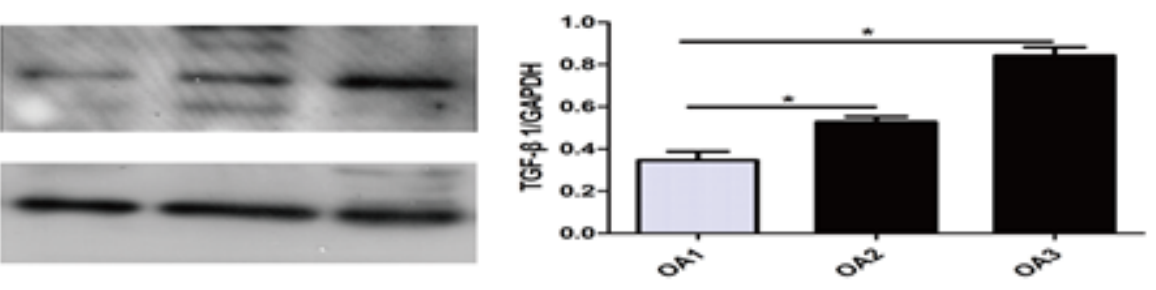

C

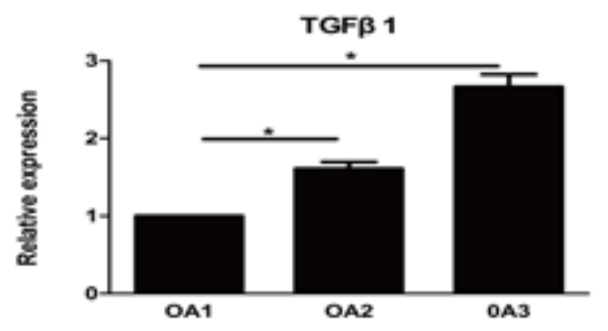

Figure 3

Immunohistochemical (left) and quantitative (right) analyses of Nestin and Osterix (brown) expression (n $=5$ per group). Scale bar $=200 \mu \mathrm{m}$. (B) Expression levels of nestin and osterix proteins in the subchondral bone of the tibial plateau. (C) Real-time PCR analysis of TGF- $\beta 1$ mRNA. OA1, unbroken cartilage group; 
OA2, worn cartilage group; and OA3, stripped cartilage group. Data represent the mean \pm SD. * Indicates statistical significance $(P<0.05)$ determined by multifactorial analysis of variance.

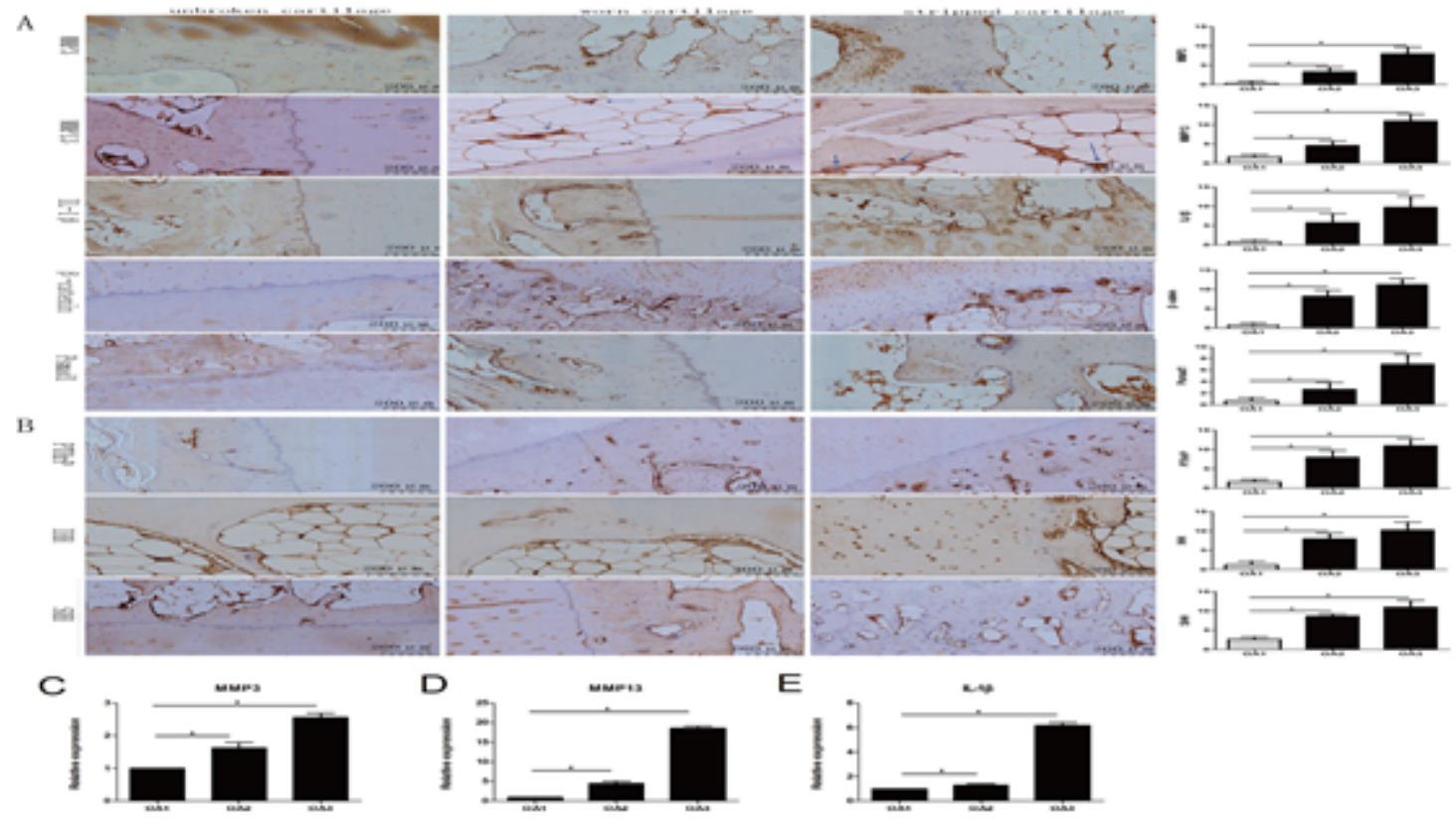

Figure 4

(A) Immunohistochemical (left) and quantitative (right) analyses of MMP-3, MMP-13, IL-1 $\beta$, $\beta$-catenin and pSmad1 (brown) expression. (B) Immunohistochemical (left) and quantitative(right) analyses of PTHrP, Indian Hedgehog $(\mathrm{IHH})$, Sonic Hedgehog $(\mathrm{SHH})(\mathrm{n}=5$ per group). Scale bar $=200 \mu \mathrm{m}$. (C-E) Real-time PCR analysis of major protein-degrading enzyme gene expression (MMP3/13, Matrix metalloproteinase3/13; IL-1 $\beta$, Interleukin-1beta). OA1, unbroken cartilage group; OA2, worn cartilage group; and OA3, stripped cartilage group. Data represent the mean \pm SD. * Indicates statistical significance $(P<0.05)$ determined by multifactorial analysis of variance.

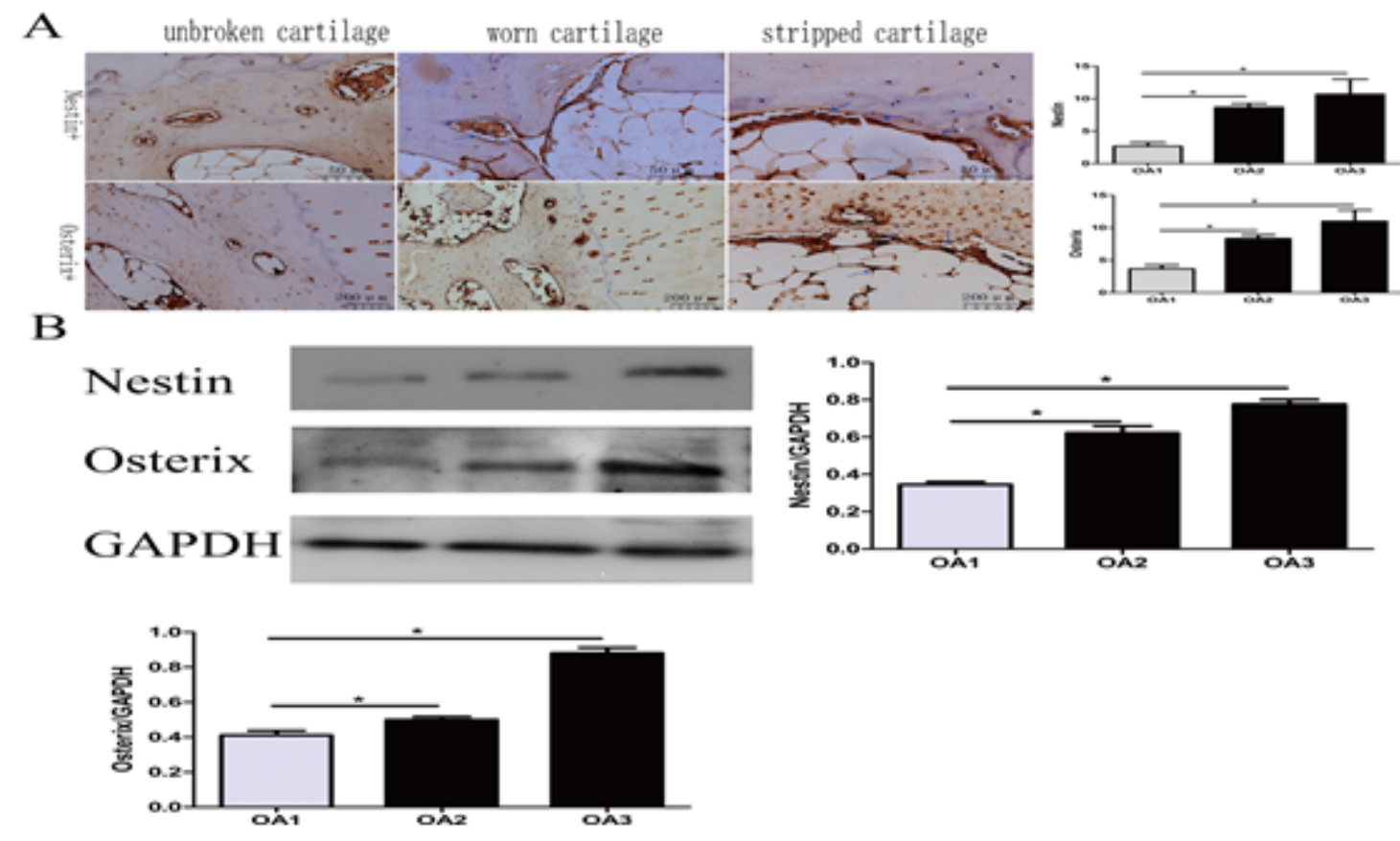


Figure 5

(A) Immunohistochemical (left) and quantitative (right) analyses of nestin and osterix (brown) ( $\mathrm{n}=5$ per group). Scale bars $=50 \mu \mathrm{m}$ and $200 \mu \mathrm{m}$, respectively. (B) Expression levels of nestin and osterix proteins in the subchondral bone of the tibial plateau. OA1, unbroken cartilage group; OA2, worn cartilage group; and $\mathrm{OA} 3$, stripped cartilage group. Data represent the mean $\pm \mathrm{SD}$. * Indicates statistical significance $(\mathrm{P}<$ 0.05 ) determined by multifactorial analysis of variance.
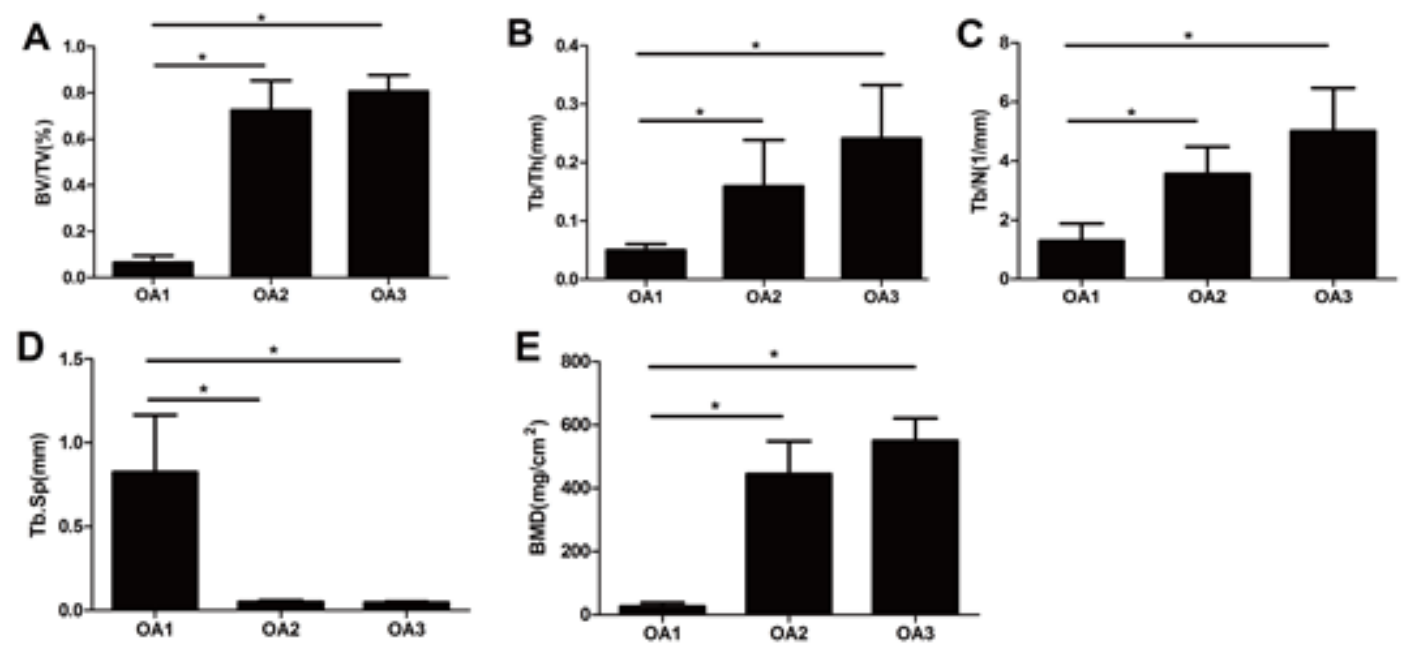

Figure 6

Comparison of subchondral bone microstructure in the cartilage exfoliation, cartilage wear and normal control groups. (A) bone volume fraction; (B) trabecular thickness; (C) trabecular bone number; and (D) trabecular bone spacing. (E):Bone density. OA1, unbroken cartilage group; $\mathrm{OA2}$, worn cartilage group; and $O A 3$, stripped cartilage group. Data represent the mean $\pm S D$. Indicates statistical significance $(P<0.05)$. 